Universidade Tecnológica Federal do Paraná - UTFPR

Campus Ponta Grossa - Paraná - Brasil

ISSN: 1981-3686/ v. 08, n. 01: p. 1216-1226, 2014

D.O.I.: $10.3895 / \mathrm{S} 1981-36862014000100007$
Revista Brasileira de Tecnologia

Agroindustrial

\title{
PRODUÇÃO DE FERMENTADO ALCOÓLICO MISTO DE POLPA DE AÇAÍ E CUPUAÇU: ASPECTOS CINÉTICOS, FISÍCO-QUÍMICOS E SENSORIAIS
}

\section{PRODUCTION OF ALCOHOLIC FERMENTED MIXED PULP AND AÇAÍ CUPUAÇU: KINETIC ASPECTS, PHYSICOCHEMICAL AND SENSORY}

\author{
Adejanildo da Silva Pereira ${ }^{1}$; Rafael Alves da Silva $\operatorname{Costa}^{2}$; Lucas Britto Landim ${ }^{3}$; Normane Mirele Chaves \\ da Silva ${ }^{4}$; Maycon Fagundes Teixeira Reis ${ }^{5}$ \\ ${ }^{1,2}$ Graduação em Tecnologia em Agroindústria do Instituto Federal de Educação, Ciência e Tecnologia \\ Baiano - Guanambi - Bahia - Brasil \\ ${ }^{3,4,5}$ Instituto Federal de Educação, Ciência e Tecnologia Baiano - Guanambi - Bahia - Brasil \\ normanechaves@yahoo.com
}

\begin{abstract}
Resumo
O Brasil é um dos maiores produtores mundiais de frutas e também um dos que apresenta maiores perdas pós-colheita, devido ao pouco investimento em medidas tecnológicas que aperfeiçoe melhor a produção e distribuição destes produtos. O emprego destas matérias primas para elaboração de bebidas fermentadas representa uma alternativa viável para o seu melhor aproveitamento e agregação de valor da mesma. Deste modo o objetivo deste trabalho foi elaborar um fermentado misto de polpas de açaí e cupuaçu e avaliar seus aspectos cinéticos, físico-químicos e sensoriais. As polpas utilizadas no estudo foram adquiridas no comercio de Guanambi-BA e posteriormente conduzidas ao laboratório de Bromatologia do IF Baiano, Campus Guanambi, onde foram processadas para a obtenção do fermentado misto. O fermentado foi monitorado diariamente avaliando-se a acidez total titulável, os sólidos solúveis totais $\left({ }^{\circ}\right.$ Brix) e grau alcoólico $\left({ }^{\circ} \mathrm{GL}\right)$ durante um período de 10 dias. Após o término do processo fermentativo o produto obtido foi submetido às análises físico-químicas e sensoriais. Os resultados para as análises físico-químicas mostraram que o produto estava dentro dos padrões estabelecidos pela legislação vigente e com grande similaridade com outros fermentados reportados na literatura. Quanto aos parâmetros cinéticos observou-se que a levedura comercial Saccharomyces cerevisiae apresentou bom desempenho no processo de fermentação alcoólica, também se assemelhando com o observado por outros autores. A avaliação sensorial indicou que o produto foi bem aceito, visto que as maiores porcentagem de resposta dos provadores ficaram entre os termos hedônicos 5 a 7 (gostei a gostei muitíssimo), além de um alto percentual de intenção de compra $(96,6 \%)$. Desta forma o fermentado misto de açaí com cupuaçu representa uma alternativa para o aproveitamento dos frutos bem como um novo produto com potencial para ser inserido no mercado.
\end{abstract}

Palavras-chave: bebida mista; fermentação alcoólica; caracterização.

\section{Introdução}

O Brasil é um dos países que apresenta maior produção mundial de frutas. Entretanto, o desperdício pós-colheita de algumas culturas gera muitos prejuízos. Deste modo, existe a necessidade de se desenvolver processos tecnológicos que permitam a redução das perdas pós-colheita e que ao mesmo tempo proporcionem o aumento na renda do produtor rural (DIAS et al., 2003; GOMES, 2007). O emprego de polpas de frutas para elaboração de bebidas fermentadas representa uma alternativa de aproveitamento destas matérias-primas, evitando desperdícios e agregando valor aos mesmos. 
As bebidas fermentadas de frutas constituem produtos promissores como tem mostrado diversas pesquisas de aceitação. Muitos países Europeus produzem diversos fermentados pelo mesmo processo de fabricação, sendo a maça, a pêra, a groselha, a framboesa e a cereja as mais utilizadas. Já nos países tropicais frutas como ao laranja, abacaxi, manga e caju fornecem fermentados bastante apreciados e saborosos (MUNIZ et al., 2002).

Produtos mistos de frutas também vêm ganhando mercado, sendo este um advento tecnológico com uma série de vantagens, tais como, a promoção de melhorias das características sensoriais através da combinação de vários aromas e sabores; aumento do valor nutricional com o enriquecimento de nutrientes das frutas utilizadas; além de estimulo ao desenvolvimento do setor produtivo com a elaboração de novos produtos (SILVA et al., 2006).

Os frutos do açaizeiro e o cupuaçuzeiro apresentam grande potencial para a elaboração de fermentado misto, devido principalmente às suas características sensoriais exóticas. Estas são plantas oriundas da floresta amazônica, e desde muito tempo os seus frutos têm sido utilizados para alimentação da população ribeirinha e de classe sociais mais baixas desta região. A produção de fermentado com mistura destes frutos promove uma harmonia entre os sabores diversificados dos mesmos melhorando deste modo as características sensoriais da bebida.

Desta forma, o presente trabalho teve como objetivo, a produção de um fermentado alcoólico misto de açaí com cupuaçu e o estudo dos seus aspectos cinéticos, físico-químicos e sensoriais.

\section{Material e Métodos}

O experimento foi realizado no laboratório de Bromatologia do Instituto Federal de Educação, Ciência e Tecnologia Baiano, Campus Guanambi. Foram utilizadas polpas industrializadas de açaí e cupuaçu comercializadas na cidade de Guanambi-BA.

\section{Caracterização microbiológica das polpas}

Foram realizadas as análises de bactérias aeróbias mesófilas, bolores e leveduras, coliformes totais, coliformes termotolerantes e salmonelas seguindo os procedimentos metodológicos recomendados pela Associação Americana de Saúde Pública (American Public Health Association APHA).

\section{Elaboração do fermentado}

As polpas foram diluídas na proporção de $12,5 \%$ de polpa de açaí, 12,5\% de polpa de cupuaçu e $75 \%$ de água. Em função do baixo teor de sólidos solúveis, especialmente após a diluição da polpa (2,0 ${ }^{\circ}$ Brix), foi necessário realizar uma chaptalização no mosto para $24,0{ }^{\circ}$ Brix. Foram obtidos $10 \mathrm{~L}$ de mosto, o qual foi pasteurizado $\left(65{ }^{\circ} \mathrm{C} / 30\right.$ minutos $)$ e posteriormente sulfitado com $200 \mathrm{mg} / \mathrm{L}$ de metabissulfito de sódio, onde foi mantido em repouso por 2 horas. 
O inóculo foi preparado utilizando-se o fermento liofilizado de panificação formado pela levedura Saccharomyces cerevisiae na quantidade de $4 \mathrm{~g} / \mathrm{L}$ de mosto (HASHIZUME, 1991). O pé de cuba foi preparado a partir de $10 \%$ do volume total do mosto, sendo este mantido em repouso durante 6 horas para a ativação das leveduras. Após este tempo o restante do mosto foi inoculado e transferido para os reatores.

A fermentação foi conduzida em batelada e os reatores foram colocados dentro de uma incubadora (B.O.D, Marca-Superolim), onde se manteve a temperatura de $28{ }^{\circ} \mathrm{C}$ durante 10 dias. Após este período o fermentado foi transferido para outro recipiente, onde foi filtrado em filtro de algodão.

Após estas etapas foi realizada a clarificação do fermentado, no intuito de diminuir a turbidez do mesmo. Este procedimento foi efetuado mediante a utilização de uma solução de gelatina incolor e sem sabor $10 \%$, sendo utilizada uma quantidade de aproximadamente $6 \mathrm{~g} / \mathrm{L}$, o que coincide com o realizado por outros autores como vinho de laranja ( CORAZZA et al., 2001) e vinho de cajá (DIAS, 2003).

Após a clarificação o fermentado misto de açaí com cupuaçu foi pasteurizado $\left(65{ }^{\circ} \mathrm{C} / 30\right.$ minutos) para inibir o processo fermentativo, sendo posteriormente resfriado e envasado em garrafas de vidro até o momento da análise sensorial e caracterização físico-química.

\section{Parâmetros cinéticos da fermentação alcoólica}

O processo fermentativo foi monitorado durante todo o tempo determinando-se a acidez total titulável, os sólidos solúveis totais ( ${ }^{\circ}$ Brix) e o Grau alcoólico $\left({ }^{\circ} \mathrm{GL}\right)$. As análises foram realizadas diariamente até o término da fermentação, a qual durou 10 dias, seguindo a metodologia do Instituto Adolfo Lutz (2008).

\section{Caracterização físico-química do fermentado}

O fermentado foi analisado quanto ao grau alcoólico, o pH, a acidez total titulável, a acidez volátil, acidez fixa, o extrato seco total, os açúcares redutores e as cinzas seguindo a metodologia do Instituto Adolfo Lutz (2008).

\section{Caracterização microbiológica do fermentado}

Foram efetuadas apenas as análises de coliformes totais e termotolerantes para demonstrar que o processo de elaboração do produto foi realizado dentro de condições sanitárias adequadas (APHA, 1984).

\section{Análise sensorial do Fermentado}

O teste sensorial foi realizado com 60 provadores não treinados, professores, alunos e servidores, no Laboratório de Análise Sensorial de alimentos do IF Baiano. A amostra do fermentado foi 
avaliada em relação aos atributos cor, sabor, aroma e impressão global por meio de uma escala hedônica estruturada de 7 pontos com extremos em gostei muitíssimo e desgostei muitíssimo e teste de atitude de compra.

\section{Resultados e discussão}

\section{Caracterização microbiológica das polpas}

Os resultados obtidos nas análises microbiológicas de contagem de bactérias totais, fungos filamentosos e leveduras, coliformes a $35^{\circ} \mathrm{C}$ e $45^{\circ} \mathrm{C}$ e Salmonella sp, para as polpas de frutas de açaí e cupuaçu estão apresentados na Tabela 1. Os valores encontrados mostraram que as polpas estavam dentro daqueles permitidos pela Resolução RDC $\mathrm{n}^{\mathrm{0}} 12$, de 02 de janeiro de 2001, que aprova o regulamento técnico sobre padrões microbiológicos para alimentos (BRASIL, 2001).

Tabela 1 - Caracterização microbiológica das polpas de açaí e cupuaçu.

\begin{tabular}{lcc}
\hline \multicolumn{1}{c}{ Análises } & \multicolumn{2}{c}{ Resultados } \\
\cline { 2 - 3 } & Açaí & Cupuaçu \\
\hline Contagem de bactérias totais & $33,26 \times 10^{2} \mathrm{UFC} / \mathrm{g}$ & $81,93 \times 10^{2} \mathrm{UFC} / \mathrm{g}$ \\
Fungos filamentosos e leveduras & $3,27 \times 10^{1} \mathrm{UFC} / \mathrm{g}$ & $4,22 \times 10^{1} \mathrm{UFC} / \mathrm{g}$ \\
Coliformes a $35^{\circ} \mathrm{C}$ & Ausente & Ausente \\
Coliformes a $45^{\circ} \mathrm{C}$ & Ausente & Ausente \\
Salmonella sp & Ausente em $25 \mathrm{~g}$ & Ausente em $25 \mathrm{~g}$ \\
\hline
\end{tabular}

A baixa contagem microbiana nas polpas de cupuaçu e açaí pode ser atribuída à boa qualidade da matéria-prima empregada na fabricação do produto, além do valor reduzido de $\mathrm{pH}$ dos frutos e da destruição de microrganismos promovida pela pasteurização, resfriamento e congelamento subsequentes.

Freire et al. (2009) investigaram a qualidade microbiológica de 3 marcas de polpas de cupuaçu congeladas e através dos dados concluiu que as três marcas de polpa apresentaram qualidades microbiológica satisfatórias.

\section{Parâmetros cinéticos da fermentação alcoólica}

Nas figuras 1 a 4 encontra-se o comportamento cinético da acidez total expressa em meq/L, dos sólidos solúveis totais ( $\left.{ }^{\circ} \mathrm{Brix}\right)$ e do grau alcoólico $\left({ }^{\circ} \mathrm{GL}\right)$ observados na fermentação do mosto misto de açaí com cupuaçu respectivamente .

Na curva da acidez, (Figura 1) observa-se que houve um aumento acentuado nos primeiros 4 dias de avaliação, havendo após este tempo a estabilização. Este comportamento foi diferente ao encontrado por Paula et al. (2011), os quais observaram um aumento gradativo deste parâmetro durante a fermentação. 


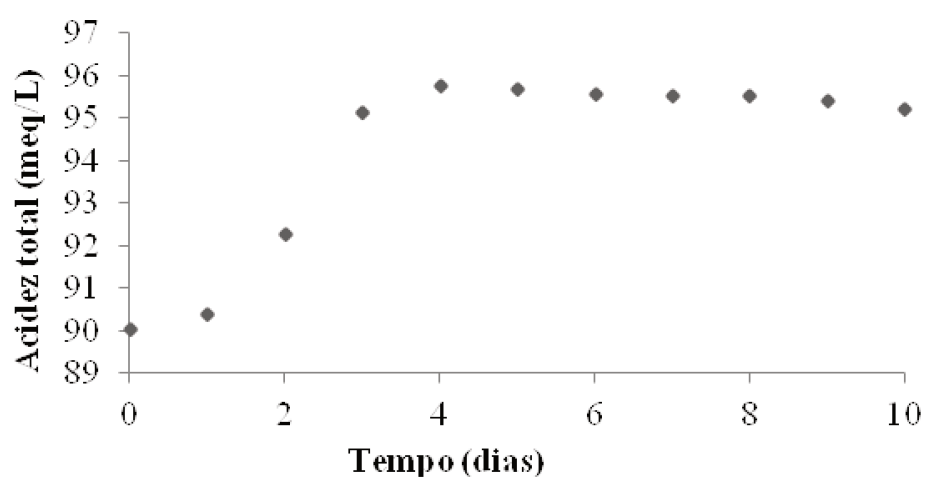

Figura 1 - Evolução da acidez total durante a fermentação do vinho misto de açaí com cupuaçu.

A acidez total possui grande importância nas características físico-químicas e sensórias dos vinhos por impedir o desenvolvimento de bactérias no meio, as quais são as principais responsáveis pelas alterações nos mostos.

Na Figura 2, verifica-se a cinética de consumo do substrato (açúcares) em função do tempo de fermentação. Durante o processo houve um baixo consumo de substrato no primeiro dia, em decorrência da adequação dos microrganismos no meio. A partir deste período foi possível notar a redução dos níveis de açucares e consequentemente a formação do produto. A taxa de consumo do substrato teve seu pico entre $2^{\circ}$ e $3^{\circ}$ dia sendo reduzido o crescimento dos microrganismos após este tempo.

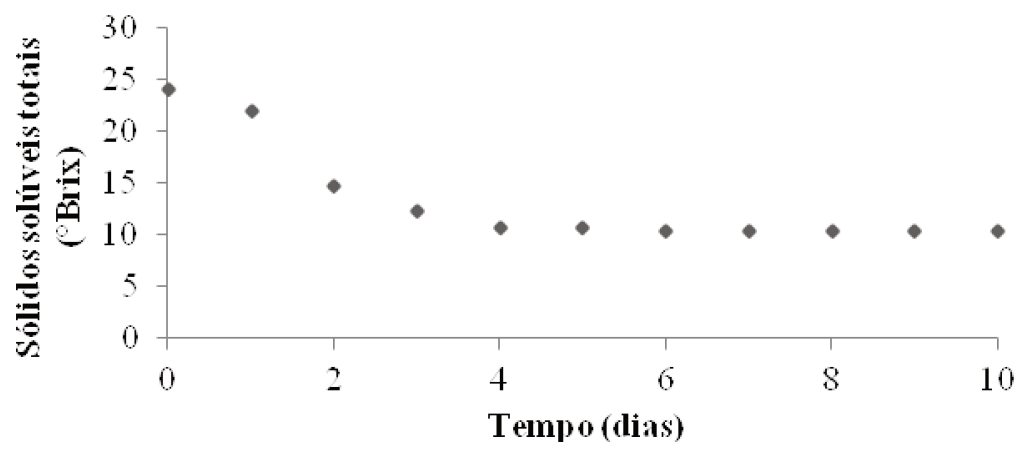

Figura 2 - Evolução do teor de sólidos solúveis durante a fermentação do vinho misto de açaí com cupuaçu.

Neto et al. (2010) estudando a produção de fermentado alcoólico de jaca observou que nos cinco primeiros dias houve um rápido consumo dos substratos. Observou-se ainda que houve a estabilização do teor de sólidos solúveis após este período.

Hoffmann et al. (2012) estudando a cinética do fermentado de ameixa, verificou a estabilização das concentrações de substrato, em torno da $98^{\text {a }}$ hora de fermentação. Observou ainda que durante o processo fermentativo houve uma estabilidade do consumo de substrato nas primeiras 10 horas, sendo a partir deste tempo verificado um aumento na redução dos níveis de açúcares.

Rodrigues et al. (2012) estudando o perfil cinético da fermentação alcoólica da carambola também verificou estabilização do consumo de substrato a partir da $98^{\mathrm{a}}$ hora de fermentação. 
Na Figura 3 é apresentada a curva do grau alcoólico $\left({ }^{\circ} \mathrm{GL}\right)$, em função do tempo de fermentação, onde é possível observar um aumento considerável nos primeiros quatro dias de fermentação e estabilização após este tempo.

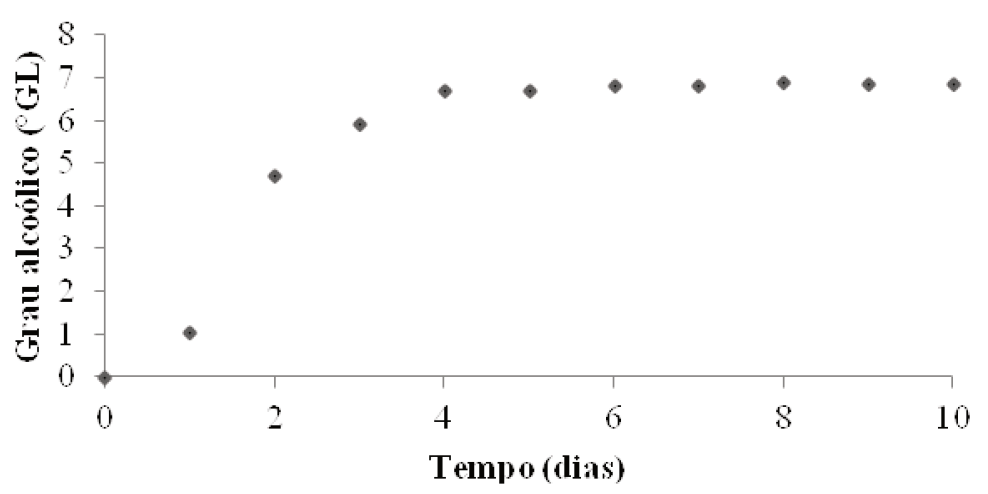

Figura 3 - Evolução do grau alcoólico durante a fermentação do vinho misto de açaí com cupuaçu.

Fontan et al. (2011) verificou aumento significativo na velocidade de conversão de substrato em etanol a partir da décima hora de fermentação, havendo a estabilização em torno de $48^{\mathrm{a}}$ hora.

\section{Análises físico-químicas do fermentado}

As análises físico-químicas realizadas no fermentado demonstraram que o produto está em conformidade com a Portaria $\mathrm{N}^{\circ} 64$ do Ministério da Agricultura Pecuária e Abastecimento (MAPA), que aprova o regulamento técnico para a fixação dos padrões de identidade e qualidade para os fermentados de frutas, Tabela 2 (BRASIL, 2008).

Tabela 2 - Caracterização físico-química do fermentado misto de açaí com cupuaçu e seus respectivos limites legais.

\begin{tabular}{lcc}
\hline \multicolumn{1}{c}{ Parâmetros } & Resultados & Limites* $^{*}$ \\
\hline Grau alcoólico $\left(\% \mathrm{v} / \mathrm{v}\right.$ a $\left.20^{\circ} \mathrm{C}\right)$ & $6,80 \pm 0,06$ & $\geq 4,00 \mathrm{e} \leq 14,00$ \\
Acidez total $(\mathrm{meq} / \mathrm{L})$ & $87,77 \pm 0,10$ & $\geq 50,00 \mathrm{e} \leq 130,00$ \\
Acidez fixa $(\mathrm{meq} / \mathrm{L})$ & $79,92 \pm 0,08$ & $\geq 30,00$ \\
Acidez volátil $(\mathrm{meq} / \mathrm{L})$ & $7,84 \pm 0,12$ & $\leq 20,00$ \\
Extrato seco $(\mathrm{g} / \mathrm{L})$ & 56,98 & - \\
Cinzas $(\%)$ & $0,34 \pm 0,11$ & - \\
Açúcares redutores $(\%$ de glicose) & $1,54 \pm 0,04$ & - \\
\hline Os limites utilizados nesta tabela foram extraídos da Portaria $\mathrm{N}^{\circ}$ 64, de 23 de abril de 2008, que aprova o regulamento técni co para a fixação dos
\end{tabular}
padrões de identidade e qualidade para os fermentados de frutas.

O teor alcoólico da bebida apresentou-se abaixo dos resultados obtidos de outras frutas reportados na literatura, como é caso do fermentado de ata, ciriguela e mangaba elaborado por Muniz et al. (2002) que atingiram teores alcoólicos de $8,4{ }^{\circ} \mathrm{GL}, 10,0{ }^{\circ} \mathrm{GL}$ e $9,8{ }^{\circ} \mathrm{GL}$, respectivamente. $\mathrm{O}$ valor mais baixo de grau alcoólico observado no presente trabalho pode esta relacionada à principal fonte de carboidrato utilizada pela levedura, que como o teor de sólidos solúveis totais das polpas diluídas em 
água foi 2,0 ${ }^{\circ}$ Brix, a principal fonte de substrato para a levedura era a sacarose. Para consumir a sacarose a Saccharomyces cerevisiae precisa hidrolisá-la a glicose e frutose antes de ser metabolizada a etanol, o que diminui a atividade metabólica deste microrganismo (PAULA, 2011).

Os valores para acidez total, acidez fixa e acidez volátil encontrados estão de acordo com o estabelecido pela Portaria No 64 (BRASIL, 2008). Entretanto os valores obtidos estão abaixo daqueles encontrados por Asquiere et al. (2008) e Paz et al. (2007) na elaboração do fermentado de jaca e fermentado de kiwi respectivamente.

Os valores encontrados para o extrato seco total são baixos se comparados com os valores do fermentado de jaca elaborado por Asquiere et al. (2008) que foi 96,80 g/L. Os baixos conteúdos de extrato seco esta relacionado com o processo de clarificação que reduz em grande quantidade os sólidos em suspensão.

Os valores de cinzas para o fermentado do presente trabalho também apresentou valor abaixo do encontrado por Paz et al. (2007) para o fermentado de kiwi (3,07 g/L) e aos encontrados por Santos et al (2005) para fermentado de acerola $(4,0 \mathrm{~g} / \mathrm{L})$. Segundo Neto et al. (2006), essa diferenças observadas são decorrentes, provavelmente, de má fermentação ou da presença de minerais estranhos à fruta.

Quanto aos açúcares redutores encontrados, estes também estão abaixo dos observados por Paz et al. (2007) para o fermentado de kiwi (8,28 g/L).

\section{Análises microbiológicas do fermentado}

Os resultados da caracterização microbiológica do fermentado misto de misto de açaí com cupuaçu estão apresentados na Tabela 3.

Tabela 3- Análises microbiológicas do fermentado misto de açaí com cupuaçu.

\begin{tabular}{ll}
\hline \multicolumn{1}{c}{ Análises } & Resultados \\
\hline Coliformes totais & Ausente \\
Coliformes termotolerantes & Ausente \\
\hline
\end{tabular}

Os resultados obtidos mostraram que o fermentado misto foi elaborado sob condições sanitárias adequadas, pelo fato de haver à ausência dos microrganismos pesquisados, atendendo desta forma a Resolução RDC $\mathrm{n}^{\circ} 12$, de 02 de janeiro de 2001, que aprova o regulamento técnico sobre padrões microbiológicos para alimentos (BRASIL, 2001).

Rodrigues et al., (2011) estudando o perfil higiênico-sanitária de amostras de vinho de açaí (euterpe oleracea) comercializado na "festa da juçara", na cidade de São Luís/MA observaram que as amostras encontravam-se inadequadas à legislação vigente, concluindo que há necessidade de se adotar medidas para assegurar a elaboração de um produto com estabilidade microbiológica que não promovam danos a saúde do consumidor. 


\section{Caracterização sensorial}

As figuras 4 e 5 mostram as porcentagens de respostas do teste de aceitação do vinho misto de açaí com cupuaçu com relação a cor, aroma, sabor, impressão global e para o teste Atitude de compra.

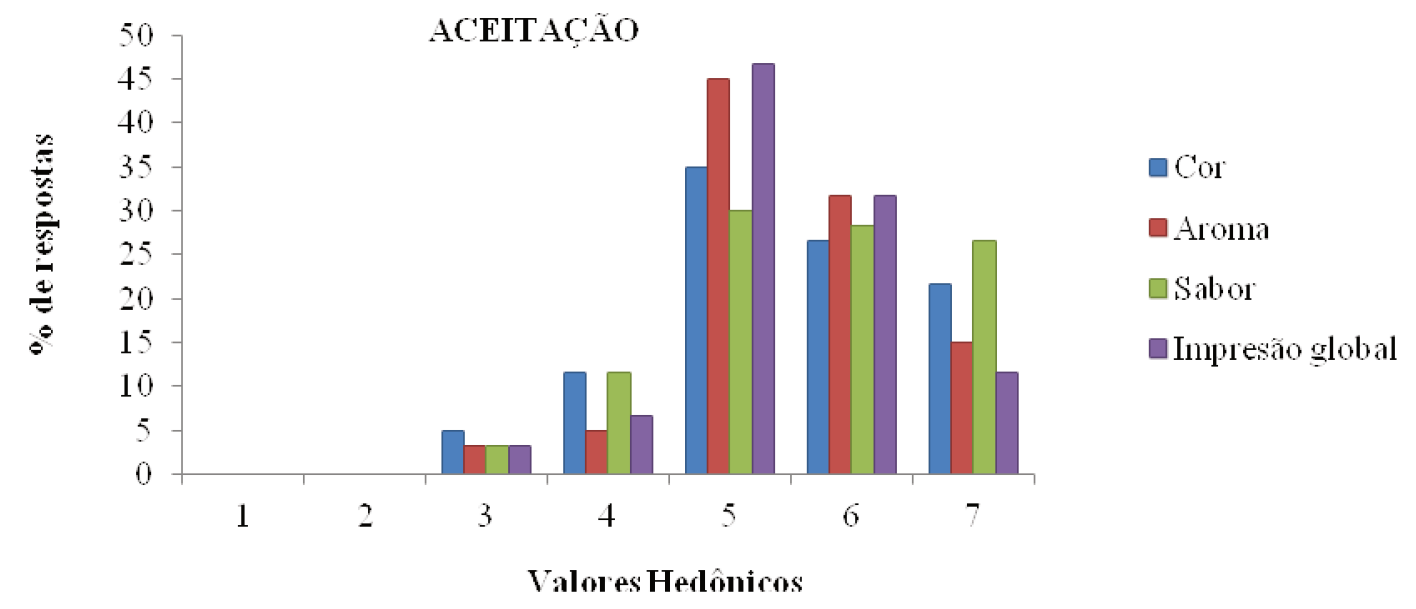

Figura 4 - Histograma dos resultados da análise sensorial do fermentado misto de açaí com cupuaçu, em relação à frequência dos valores hedônicos atribuídos a cor, aroma, sabor e impressão global (7= gostei muitíssimo e $1=$ desgostei muitíssimo).

Observando o histograma (Figura 4) dos resultados da análise sensorial para o teste de aceitação do vinho misto, em relação à frequência dos valores hedônicos atribuídos a cor, pode-se verificar que os maiores percentuais de respostas ficaram entre os valores hedônicos 5 (gostei) e 6 (gostei muito), sendo que apenas $5 \%$ dos provadores impuseram a nota 3 (desgostei) a este atributo. Em relação à frequência hedônica atribuídas ao aroma, pode-se observar que o maior índice de aceitabilidade também esteve nas notas 5 (gostei) e 6 (gostei muito), apresentado percentuais de respostas de $45 \%$ e $31 \%$ respectivamente. Quanto ao sabor, este foi o atributo que apresentou valores mais expressivos de respostas para a nota 7 (gostei muitíssimo) situado em aproximadamente $27 \%$. Os valores hedônicos 5 e 6 para este atributo apresentaram percentual de respostas de 30 e $28 \%$ respectivamente. Por fim a aceitação global do produto foi a que apresentou maior percentual de respostas para as notas 5 e 6 situados em aproximadamente 47 e $32 \%$ respectivamente demonstrando a boa aceitação do produto.

Na Figura 5 é apresentado o histograma dos resultados da análise sensorial em relação à frequência dos valores hedônicos atribuídos a atitude de compra para o vinho misto. Analisando o histograma observa-se que as maiores frequências de respostas estiveram nos valores hedônicos 5 (certamente compraria) e 4 (provavelmente compraria), equivalendo a um percentual de respostas de aproximadamente 52 e $28 \%$, respectivamente. Observa-se também que menos de $4 \%$ dos provadores disseram que provavelmente não compraria o produto, valor insignificante quando comparados com a soma das respostas positivas $(96,6 \%)$ situadas entre o termos hedônicos 3 a 5 (talvez comprasse/talvez 
não comprasse a certamente compraria). Verifica-se, portanto, a grande atitude de compra do produto, sendo desta forma, uma alternativa viável ao uso dos frutos do cupuaçu e açaí.

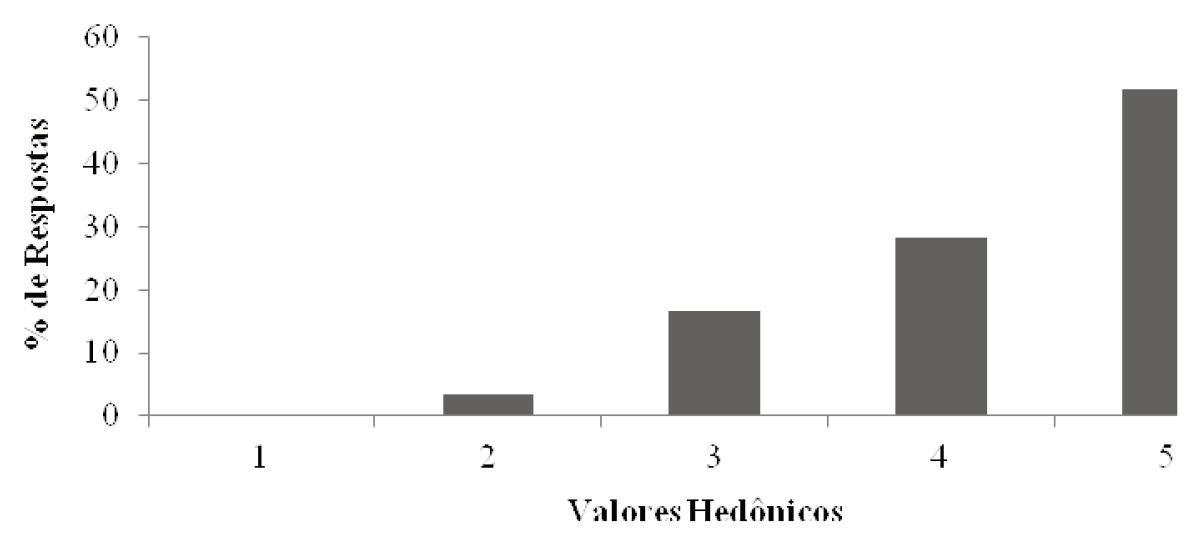

Figura 5 - Histograma dos resultados da análise sensorial do fermentado misto de açaí com cupuaçu, em relação à frequência dos valores hedônicos atribuídos a atitude de compra (5= Certamente compraria e 1 = Certamente não compraria).

Ports et al. (2008) estudando a produção de vinho misto de taperebá e goiaba também obtiveram valores positivos nos testes sensoriais realizados $(82,31 \%$ de aceitação e $72 \%$ de intenção de compra), demonstrando desta forma o grande potencial do uso de misturas de frutas na produção de bebidas alcoólicas fermentadas.

Neto et al. (2010) estudando bebida alcoólica fermentada de jaca (Artocarpus heterophyllus Lam.) também obtiveram boa aceitação para o teste sensorial realizado $(61 \%)$.

Muniz et al. (2002) estudando as bebidas fermentadas de ata, ciriguela e mangaba, também obtiveram boa aceitabilidade do produto com um índice de aceitação de 5,1,4,3 e 5,7, respectivamente.

\section{Conclusão}

A produção do fermentado misto de açaí com cupuaçu mostra-se tecnologicamente viável, uma vez que todas as características físico-químicas atendem aos limites estabelecidos pela legislação vigente, sendo o seu processo de elaboração similar ao de um vinho.

A avaliação sensorial indicou que o produto obtido teve boa aceitação, visto que a porcentagem de resposta dos provadores esteve numa frequência maior na escala hedônica de 5, 6 e 7 referindo-se à gostei, gostei muito e gostei muitíssimo, respectivamente e um alto percentual de intenção de compra $(96,6 \%)$.

As polpas de açaí e cupuaçu possuem alto potencial para produção de bebida alcoólica fermentada mista, apresentando-se como mais uma alternativa de agregação de valor na cadeia produtiva destas frutas, além de possibilitar a inserção de um novo produto no mercado. 


\begin{abstract}
Brazil is one of the largest producers of fruit and one of which has higher post-harvest losses due to low investment in technological measures that best optimize the production and distribution of these products. The use of these materials for preparation of fermented beverages represents a viable alternative to their best use and value of it. Thus the aim of this study was to develop a mixed fermented pulp of açai and cupuaçu and assess their technological aspects, physicochemical and sensory. The pulps used in this study were purchased from Guanambi the trade-Ba and subsequently sent to the laboratory where they are processed to obtain the fermented mixture. The fermentation was monitored daily by assessing the total acidity, pH, total soluble solids and alcohol content over a period of 10 days. Upon completion of the fermentation product obtained was subjected to physical and chemical analysis and sensory. The results for physical and chemical analysis showed that the product was within the standards established by law and with great similarity to other fermented reported in the literature. As for the kinetic parameters was observed that commercial yeast Saccharomyces cerevisiae showed good performance in the process of fermentation, also resembling with that observed by other authors. Sensory evaluation indicated that the product was well accepted, since the largest percentage of response among the tasters were 5-7 hedonic terms (like the extremely like), and a high percentage of purchase intent $(96.6 \%)$. Thus the fermented mixed with açai cupuaçu represents an alternative to the use of fruits as well as a new product with the potential to be placed on the market.
\end{abstract}

Key-words: mixed drink, alcoholic fermentation; characterization.

\title{
Referências
}

AMERICAN PUBLIC HEALTH ASSOCIATION. Compendium of methods for the microbiological examination of foods. 2. ed. Washington, D.C., 1984.

ASQUIERI, E. R.; RABÊLO, A. M. S.; SILVA, A. G. M.. Fermentado de jaca: estudo das características físicoquímicas e sensoriais. Ciência e Tecnologia de Alimentos, v. 28, n. 4, p. 881-887, 2008.

ASSIS NETO, E. F. A.; CRUZ, J. M. P.; BRAGA, A. C. C.; SOUZA, J. H. P. Elaboração de bebida alcoólica fermentada de jaca (Artocarpus heterophyllus Lam.). Revista Brasileira de Tecnologia Agroindustrial. Ponta Grossa-PR, v. 04, n. 02: p. 186-197, 2010. http://dx.doi.org/10.3895/s1981-36862010000200007

BRASIL. Portaria n. 64 de 23 de Abril de 2008, que Aprova os Regulamentos Técnicos para a Fixação dos Padrões de Identidade e Qualidade para as Bebidas Alcoólicas Fermentadas: Fermentado de Fruta, Sidra, Hidromel, Fermentado de Cana, Fermentado de Fruta Licoroso, Fermentado de Fruta Composto e Saquê. Brasília: Ministério da Agricultura e de Abastecimento.

BRASIL. Resolução RDC n 12, de 02 de Janeiro de 2001, que Aprova o Regulamento Técnico sobre Padrões Microbiológicos para Alimentos. Brasília: Ministério da Saúde.

CORAZZA, M. L.; RODRIGUES, D. G.; NOZAKI, J. Preparação e Caracterização do vinho de laranja. Química Nova, v. 24, n. 4, p. 449-452, 2001.

DIAS, D. R.; SCHAWN, R. F.; LIMA, L. C. O. Metodologia para elaboração de fermentado de cajá (Spondias mombin L.). Ciência e Tecnologia de Alimentos, v. 23, n. 3, p. 342, 2003.

FONTAN, R. C. I. ; VERÍSSIMO, L. A. A.; SILVA, W. S.; BONOMO, R. C. F. VELOSO, C. M. Cinética da fermentação alcoólica na elaboração de vinho de melancia. Boletim do Ceppa, Curitiba, v. 29, n. 2, p. 203-210, 2011.

FREIRE, M. T. A.; PETRUS, R. R.; FREIRE, C. M. A.; OLIVEIRA, C. A. F.; FELIPE, A. M. P. F.; GATTI, G. B. Caracterização físico-química, microbiológica e sensorial de polpa de cupuaçu congelada (Theobroma grandiflorum Schum). Brazil Journal of Food Technology, v. 12, n. 1, p. 09-16, 2009. 
GOMES, P. Fruticultura brasileira. 13 edição. São Paulo: Nobel, 2007. 446 p

HASHIZUME, T. Manual prático da fabricação de vinhos de frutas. ITAL- Instituto de tecnologia de Alimentos, Campinas-SP, 1999.

HOFFMANN, J. F.; PEREIRA' A. S.; COSTA, R. A. S.; LANDIM, L. B.; SILVA, N. M. C. Cinética e caracterização físico-química do fermentado de ameixa. In: Anais do XXII Congresso Brasileiro de Fruticultura. Bento Gonçalves-RS, 2012.

INSTITUTO ADOLFO LUTZ. Métodos físicos químicos para análise de alimentos. 4 ed. São Paulo, 2008.1020 p.

MUNIZ, C. R.; BORGES, M. F.; ABREU, F. A. P.; NASSU, R. T.; FREITAS, C. A. S. Bebidas fermentadas a partir de frutos tropicais. Boletim do CEPPA, v. 20, n. 2, p. 309-322, 2002.

NETO, A. B. T.; SILVA, M. E.; SILVA, W. B.; SWARNAKAR, R.; SILVA F. L. H. Cinética e caracterização físicoquímica do fermentado do pseudofruto do caju (Anacardium occidentale L.). Química Nova. São Paulo, v. 29, p. 489492, 2006.

PAULA, B. Obtenção e caracterização do fermentado de umbu (spondias tuberosa arr. cam.) do semiárido nordestino em escala semiindústrial. Salvador-BA, 2011. Dissertação (Mestrado em Ciência de Alimentos)- Curso de pós Graduação da Universidade Federal da Bahia- Faculdade de Farmácia.

PAZ, M. F.; SCARTAZZINI, L. S.; OGLIARI, T. C.; BURLIN, C. Produção e Caracterização do Fermentado Alcoólico de Actinidia deliciosa Variedade Bruno Produzido em Santa Catarina. In: Anais do XVI Simpósio Nacional de Bioprocessos, SINAFERM 2007. Curitiba, 2007.

PORTS, P. S.; MENDONÇA, A. P. O.; MATTIETTO, R. A. Caracterização físico-química e sensorial de vinho misto de taperebá e goiaba, Embrapa, 2008.

RODRIGUES, E. P.; PEREIRA' A. S.; SILVEIRA, P. T. S.; SANTOS, V. N.; MARTINS, M. W. R.; SILVA, N. M. C. Cinética e caracterização físico-química do fermentado de Carambola. In: Anais do III Simpósio Internacional de Plantas Medicinais e Nutracêuticos e III Conferencia do Instituto Nacional de Ciência e Tecnologia de Frutos Tropicais. Aracaju-SE, 2012.

RODRIGUES, L. C; ALVES, M. M. P. B.; NASCIMENTO, A. R.; CHAVES, N. P.; PEREIRA, D. B.; FERREIRA, E. M. Perfil higiênico-sanitária do vinho de açaí (euterpe oleracea) comercializado na "festa da juçara", na cidade de são Luís - MA. Higiene Alimentar, 2011.

SANTOS, S. C.; ALMEIDA, S. S.; TOLEDO, A. L.; SANTANA, J. C. C.; SOUZA, R. R. Elaboração e análise sensorial do fermentado de acerola (Malpighia punicifolia L.). Brazilian Journal of Food Technology, p. 47-50, 2005.

SILVA, F. V. G.; MAIA, G. A.; SOUSA, P. H. M.; LIMA, A. S.; COSTA, J. M. C.; FIGUEIREDO, E. A. T. Avaliação da estabilidade de bebida mista elaborada com água de coco e suco de maracujá. Acta Scientiarum. Technology Maringá, v. 28, n. 2, p.191-197, 2006.

Submetido em 15 fev. 2013, Aceito para publicação em 20 dez. 2013. 